\title{
EFFECTS OF SUPPLEMENTAL LYSINE ON PERFORMANCE, ANTIBODY TITER AND RECTAL TEMPERATURE IN RESPONSE TO A MODIFIED-LIVE VIRAL VACCINE IN NEONATAL CALVES
}

\author{
${ }^{1}$ Kate Sharon, ${ }^{1}$ Glenn Duff, ${ }^{3}$ Jeff Dailey, ${ }^{3}$ Jeff Carroll, ${ }^{2}$ Jonathan Hilmer and ${ }^{2}$ Brian Bothner \\ ${ }^{1}$ Department of Animal and Range Sciences, \\ ${ }^{2}$ Department of Chemistry and Biochemistry, \\ Montana State University, Bozeman, Montana, USA \\ ${ }^{3}$ Livestock Issues Research Unit, USDA-ARS, Lubbock, Texas, USA
}

Received 2013-09-26; Revised 2014-05-30; Accepted 2014-06-02

\begin{abstract}
Infectious Bovine Rhinotracheitis (IBR), caused by bovine herpesvirus-1, contributes significantly to economic losses in the dairy and beef cattle industry. Lysine has been shown reduce virulence of herpesviruses in felids and humans. Our objective was to evaluate the effects of supplemental lysine on serum IBR antibody titer and rectal temperature in response to a modified-live Intranasal (IN) or Intramuscular (IM) respiratory-virus vaccination. Sixty-four neonatal Holstein bull calves $(7 \pm 2 \mathrm{~d}$ of age; $\mathrm{BW}=37 \pm 4.2 \mathrm{~kg}$ ) were used in a completely randomized design. Calves were fed milk replacer supplemented with either $17 \mathrm{~g} / \mathrm{d}$ L-lysine monohydrochloride (LYS; 28 calves) or an equivalent amount of casein (CAS; 28 calves) for $42 \mathrm{~d}$. Calves were then vaccinated with either an IN IBR-Parainfluenza virus-3 (PI3) or an IM (IBR-PI3-bovine viral diarrhea type I and II, bovine respiratory syncytial virus) modified-live vaccine on $\mathrm{d} 36$. A control group ( 8 calves) received no supplement or vaccination. All calves were housed in individual calf pens $(1.2 \times 2.1 \mathrm{~m})$. Daily feed intakes were monitored and BW measured weekly. Calves were bled on d 0,35, 36, 37 and 42. Temperature data loggers were attached to rectal probes and temperatures were recorded every $5 \mathrm{~min}$ from d 28 to d 42. No significant differences were determined for average performance, rectal temperature, or IBR antibody titers with either IN or IM vaccinations between LYS and CAS treated calves ( $p>0.10)$. However, serum urea nitrogen and the ratio of serum lysine: Arginine increased $(\mathrm{p}<0.05)$ for LYS compared to CAS calves. These results suggest that supplementing lysine impacts nitrogen metabolism but does not alter the response to IBR vaccination or animal performance in neonatal Holstein calves.
\end{abstract}

Keywords: Holstein Calves, Bovine Herpesvirus-1, Lysine, Vaccination

\section{INTRODUCTION}

The susceptibility of the respiratory tract to bacterial disease following a viral infection is a matter unresolved. Bovine Herpesvirus-1 (BHV-1) is one of the foremost infections contributing to Bovine Respiratory Disease (BRD; Nandi et al., 2009). An infection of BHV-1 can lead to Infectious Bovine Rhinotracheitis (IBR), suppressing the immune system and increasing the risk fora secondary bacterial infection (Yates, 1982). Herpes viruses are difficult to eradicate due to the establishment of latency after exposure (Nandi et al., 2009). Times of stress, such as those experienced during shipping and processing, can stimulate the virus to emerge from latency, inducing diseaseand further spreading the virus (Perez et al., 2005). Bovine herpesvirus- 1 is very common; cattle herds of over 400 head may have BHV-1 prevalence of over $85 \%$ (Raaperi et al., 2010). Vaccines are readily available for Corresponding Author: Sharon, K.P., Department of Animal and Range Sciences, Montana State University, Bozeman 59717, Montana, USA 
BHV-1 that attempt to provide enough immunity to avoid reactivation of the disease. Although vaccination is common, humoral immunity is not always sufficient and reactivated-induced disease puts cattle at risk for developing BRD (Jones and Chowdhury, 2007).

There is evidence that lysine supplementation decreases the incidence and severity of herpesvirusassociated disease (Maggs et al., 2000). In vitro studies have shown lysine has a replication-inhibiting capability of the herpes virus (Maggs et al., 2000). Since IBR is the result of a herpes virus infection, there may be an altered response to the common IBR vaccination when lysine is supplemented at concentrations exceeding requirements of $17 \mathrm{~g} / \mathrm{d}$ determined by Hill et al. (2007). The objective of this study was to investigate the effects of a lysine supplementation on a modified-live viral respiratory vaccine.

\section{MATERIALS AND METHODS}

Procedures were reviewed and approved by the Montana State University Agriculture Care and Use Committee, 2012-AA01.

\subsection{Animals, Treatments and Diets}

Sixty-four Holstein calves $(7 \pm 2 \mathrm{~d}$ of age; $\mathrm{BW}=$ $37 \pm 4.2 \mathrm{~kg}$ ) were used in a completely randomized design. Sixteen calves were purchased from a commercial Montana dairy and were transported (approximately $30 \mathrm{~min} ; 30 \mathrm{~km}$ ) to the Montana State University facility after receiving their morning feeding. Forty-eight calves were purchased from a commercial Idaho calf ranch and were transported (approximately $6 \mathrm{~h}$ and $660 \mathrm{~km}$ ) after their morning feeding to the Montana State University facility. Upon arrival, calves were weighed and randomly assigned to treatments including: LYS, lysine supplemented, CAS, casein supplemented and CON, control (no supplementation). Calves received either an IN, intranasal, or IM, intramuscular modified-live viral respiratory vaccination. Calves in the control group received no vaccination. Calves were housed in individual pens $(1 \times 2 \mathrm{~m})$ fitted with feed and water buckets and nose guards to eliminate calf-to-calf contact. Pens were concrete-surfaced covered with rubber mats. Crates were maintained inside at the Bozeman Agriculture and Teaching (BART) Farm with a mean temperature of $15^{\circ} \mathrm{C}$.

All calves were fed a commercial milk replacer (Vigortone, Nurture Pinnacle, Brookville, OH; DM: 95.7\%; CP: 26.6\%; crude fat: $18.7 \%$; ash: $6.4 \%$ ) at 0.45 $\mathrm{kg} / \mathrm{d}$ per calf twice daily at 0700 and 1900 for $42 \mathrm{~d}$. Milk replacer was mixed based on weight and at a concentration of $12 \%$ powder (as-fed) (Milk Master, Poly Tank and Polydome, Litchfield, MN). Milk replacer was fed using 2L nursing bottles (Calf Nurser Bottle, Merrick, Inc., Vadnais Heights, NM) with a rubber teat (Milk Bar Bottle Nipple, Coburn Company, Whitewater, WI) and individual bottle holders in each pen. LYS calves received $8.5 \mathrm{~g}$ of L-lysine monohydrochloride (Global Bio-Chem, Hong Kong, China) twice daily allocated to individual bottles and mixed with milk replacer. LYS calves received a total of $17 \mathrm{~g}$ head $^{-1} \cdot \mathrm{d}^{-1}$ of lysine. CAS calves received $8.5 \mathrm{~g}$ of casein allocated to individual bottles and mixed with milk replacer twice daily. CAS calves received a total of $17 \mathrm{~g}$ head $^{-1} \mathrm{~d}^{-1}$ of casein. CON calves received no supplementation. After each feeding, bottles and teats were washed with a soap, bleach and water mixture.

Additionally, calves were offered a commercial starter feed (Dairy Starter Pellet; Payback Feed, Sioux Falls, SD; DM, 97.8; ADF, 8.9; NDF, 21.9 and CP, $19.9 \%$ ) beginning on $\mathrm{d} 3$ with an initial offering of 0.2 $\mathrm{kg}$ head ${ }^{-1} \cdot \mathrm{d}^{-1}$. Amounts were increased to ensure free choice consumption. Dailyallotments of grain were fed starting at 0730 in buckets. Daily refusals were weighed prior to feeding. Offered and refused feed was weighed back daily. Each calf was supplied with a water bucket. Water was changed twice daily. Water buckets were washed with a soap, bleach and water mixture weekly.

\subsection{Data Collection}

Rectal temperatures were constantly recorded by means of an indwelling rectal temperature probes starting on d 28 and ending on d 42. Temperature data loggers were attached to the rectal probes. Temperatures were recorded every $5 \mathrm{~min}$ and averaged every hour for the duration of the study for statistical analyses.

Calves were vaccinated on $\mathrm{d} 35$ at approximately 1000 via intranasalinoculation with $2 \mathrm{~mL}$ of a modifiedlive respiratory vaccine containing BHV-1 and PI3 (Nasalgen, Merck Animal Health, Summit, NJ) or intramuscularly with $2 \mathrm{~mL}$ of a pentavalent, modifiedlive respiratory vaccine containing BHV-1, BVDV1a, BVDV2a, PI3 and BRSV (Express 5, Boehringer Ingelheim Vetmedica, Inc., Saint Joseph, MO). Control Calves $(\mathrm{CON})$ received no vaccination.

Body weights were obtained on d 0, 1, 7, 14, 21, 28, 35 and 42 prior to the 1900 feeding. Grab samples of the 
grain and milk replacer diet were collected weekly for analysis. Ingredient samples were analyzed for NDF and ADF, CF, fat and CP (Dairy One Laboratory, Ithaca, NY).

Incidence of any illnesses was recorded daily for each animal. Calves that showed signs of morbidity were treated immediately. Treatment regimen consisted of administration of tulathromyocin (Draxxin; Pfizer Animal Health) at a rate of $1.1 \mathrm{~mL}^{-1} 45.3 \mathrm{~kg}(2.5 \mathrm{mg}$ $\mathrm{kg}^{-1}$ ) and flunixinmeglumine (Banamine; Merck Animal Health) at a rate of $1.0 \mathrm{~mL}^{-1} 45.3 \mathrm{~kg}\left(2.2 \mathrm{mg} \mathrm{kg}^{-1}\right)$. All treatments including $\mathrm{d}$ of treatment, type of treatment and amount of dosage were recorded. Documentation of death was recorded byanimal ID and date of death.

Blood samples were collected via jugular venipuncture on $\mathrm{d} 0,7,14,21,28,35,36,37,39$ and 42 in vacuum tubes (Kendall Monojet; Covidien, Mansfield, Massachusetts) for all calves. Blood collection was conducted prior to the $1900 \mathrm{~h}$ feeding. Serum was centrifuged at $2,100 \times \mathrm{g}$ for $15 \mathrm{~min}$ at $20^{\circ} \mathrm{C}$ and then stored frozen at $-20^{\circ} \mathrm{C}$ until analyzed. Frozen serum was transported to the Montana State University Veterinary Diagnostic Lab (Bozeman) for determination of serum neutralizing antibodies for BHV-1, PI3, BVDV type I, BVDV type II and BRSV. Serum samples were analyzed for SUN content by a commercial assay kit (Urea Nitrogen Direct; Cat. \# 0580-250; Stanbio Laboratory, Boerne, TX). Additionally, serum samples were analyzed for serum lysine and arginine concentrations by means of mass spectrometry.

\subsection{Calculations and Statistical Analysis}

All data was analyzed using the Proc Mixed procedures of SAS (SAS Institute Inc., Cary, NC). Each calf was treated as the experimental unit. Performance data were analyzed with a model that included treatment, block and calf. Temperature, antibody titer data, serum lysine and arginine and SUN data were analyzed with a model that included treatment, calf (treatment), day and treatment $x$ day. Significance was indicated when $p<0.05$.

\section{RESULTS}

No differences $(p>0.10)$ were observed for initial $\mathrm{BW}$, final $\mathrm{BW}$, ADG, DMI or overall G: $\mathrm{F}$ across treatments (LYS, CAS and CON) shown in Table 1.

No differences were observed among treatments (LYS, CAS and CON) in vaccinated calves for IN Fig. 1 or IM in Fig. 2 for rectal temperature $(p>0.10)$ or IBR antibody titer levels ( $p>0.10$ ), Fig. 3 .

Serum urea nitrogen in Fig. $\mathbf{4}$ and the ratio of lysine: Arginine, Fig. 5 and 6, was greater for LYS compared to CAS calves.
Table 1. Effect of supplemental lysine on performance of neonatal Holstein calves

\begin{tabular}{|c|c|c|c|c|}
\hline \multirow[b]{2}{*}{ Item } & \multicolumn{4}{|c|}{ Treatment $^{1}$} \\
\hline & CAS & LYS & $\mathrm{CON}$ & SEM $^{2}$ \\
\hline Calves & 28 & 28 & 8 & - \\
\hline \multicolumn{5}{|l|}{$\mathrm{BW}, \mathbf{k g}^{\mathbf{3}}$} \\
\hline Initial & 36.5 & 36.7 & 34.4 & 1.1 \\
\hline Final & 56.9 & 59.3 & 52.4 & 2.6 \\
\hline \multicolumn{5}{|c|}{ Performance, d 0 to $42^{3}$} \\
\hline ADG, kg & 0.45 & 0.46 & 0.43 & 0.07 \\
\hline DMI, kg & 0.66 & 0.70 & 0.60 & 0.13 \\
\hline G: F & 0.94 & 0.65 & 0.69 & 0.25 \\
\hline
\end{tabular}

${ }^{1}$ Treatments were supplementation: CAS $=17 \mathrm{~g} / \mathrm{d}$ casein; LYS

$=17 \mathrm{~g} / \mathrm{d}$ L-lysine monohydrochloride; $\mathrm{CON}=$ no supplementation

${ }^{2}$ Pooled SEM

${ }^{3}$ No difference $(p>0.10)$

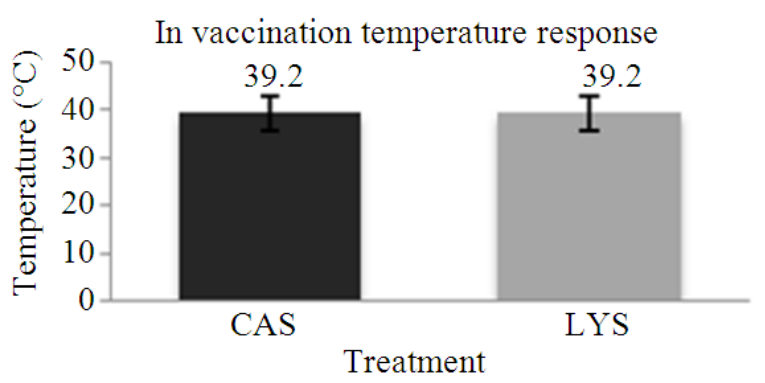

Fig. 1. Effects of IN modified-live IBR-PI3 viral vaccination on rectal temperature in calves receiving $17 \mathrm{~g} / \mathrm{d}$ of supplemental Lysine (LYS) or $17 \mathrm{~g} / \mathrm{d}$ of Supplemental Casein (CAS) in neonatal Holstein calves. Averaged rectal temperature was not significant among treatments $(\mathrm{p}>0.10)$

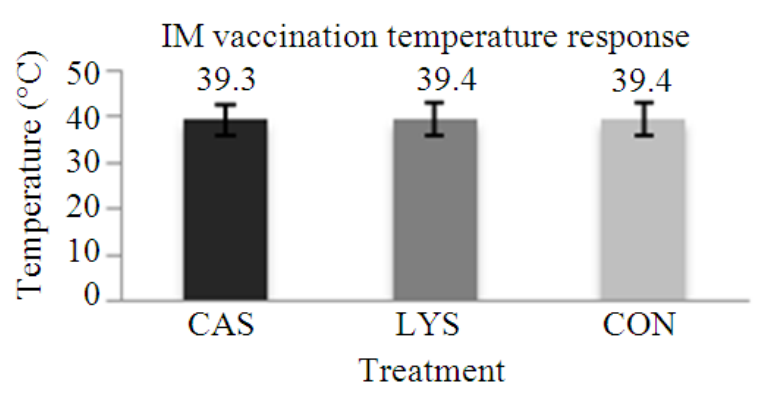

Fig. 2.Effects of IM modified-live IBR-PI3 viral vaccination on rectal temperature in calves receiving $17 \mathrm{~g} / \mathrm{d}$ of supplemental Lysine (LYS), $17 \mathrm{~g} / \mathrm{d}$ of supplemental Casein (CAS) or no supplementation (CON) in Holstein calves. Averaged rectal temperature was not significant among treatments $(\mathrm{p}>0.10)$ 


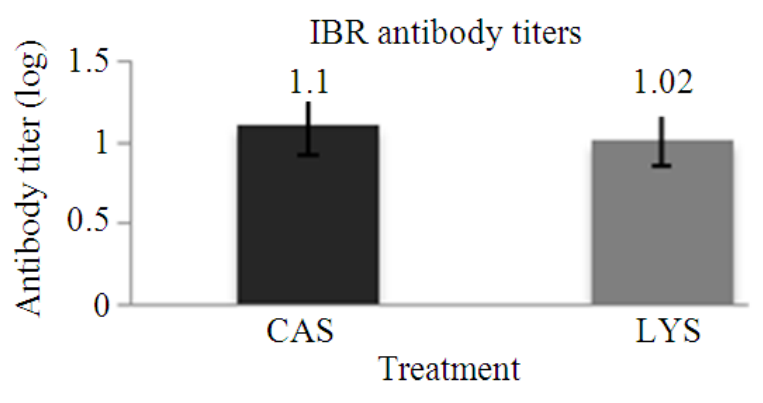

Fig. 3. Overall effects of Supplemental Lysine (LYS) or Casein (CAS) on IBR antibody titers following a modified-live viral respiratory vaccination in neonatal Holstein calves. No difference ( $p>0.10)$ between CAS and LYS calves was detected

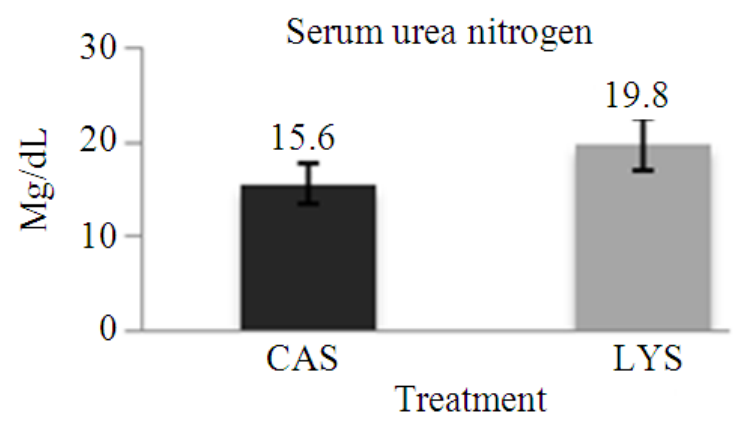

Fig. 4. Effects of supplemental Lysine (LYS) or supplemental Casein (CAS) on serum urea nitrogen in neonatal Holstein calves. Overall SUN was greater $(p>0.05)$ in LYS compared to CAS calves

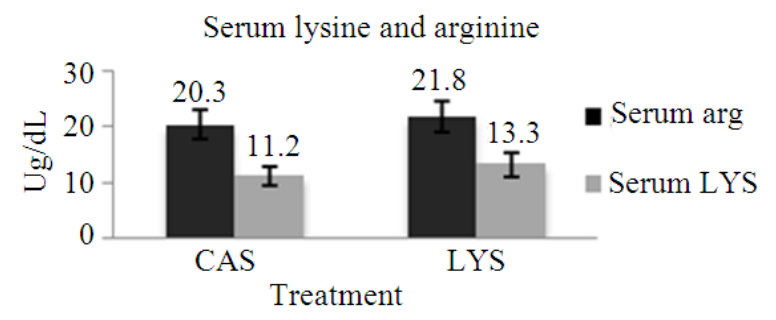

Fig. 5. Overall effects of Supplemental Lysine (LYS) or Supplemental Casein (CAS) on serum lysine and arginine levels in neonatal Holstein calves. No difference $(p>0.10)$ between CAS and LYS calves was detected for serum lysine or serum arginine

\section{DISCUSSION}

Calf performance was not affected by treatment, suggesting that no treatment group had a nutritional advantage or disadvantage in mounting immunity in response to the vaccine.

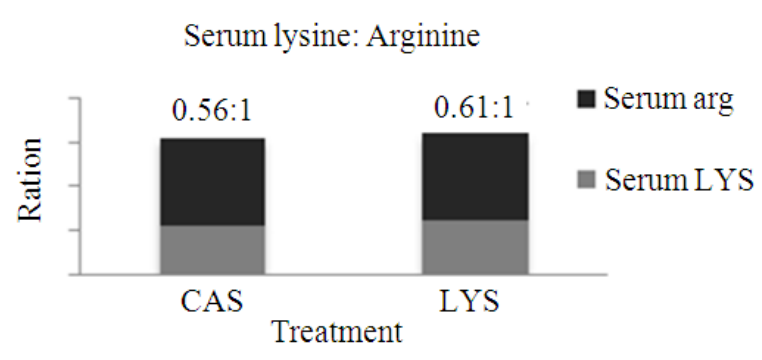

Fig. 6. Effects of supplemental Lysine (LYS) and supplemental Casein (CAS) on serum lysine: Arginine ratio in neonatal Holstein calves. Serum lysine: Arginine ratio was greater $(p<0.05)$ in LYS compared to CAS calves

Available N was equal in CAS and LYS diets; casein was fed to ensure CAS and LYS diets were isonitrogenous. All calves received at least the recommended $17 \mathrm{~g} / \mathrm{d}$ of lysine. Calves in the LYS group ingested double the amount of daily lysine requirements. Serum urea nitrogen levels were used to retrospetively diagnose biological responses to the added protein. Despite the diets of CAS and LYS groups being isonitrogenous, LYS treatment resulted in greater SUN levels. With all diets being formulated to meet nutritional requirements it can be proposed this additional lysine was simply biologically unessecary, resulting in increased SUN levels.

Lysine: Arginine ratios were greater in LYS calves group compared to CAS calves. This is important in the lysine replication inhibition of the herpesvirus. Lysine and arginine are very similar in molecular structure. For this reason, lysine may be substituted for arginine in biological pathways. This is important as the herpes virus requires arginine for replication (Maggs et al., 2000). Also contributing to lysine: Arginine ratios is lysine-arginine antagonism. Lysine-arginine antagonism has been studied in many species, although the complete mechanism has not been fully elucidated. Proposed mechanisms include an increase in renal arginase activity and inhibiton of reabsorption in the presence of high lysine levels (Chamruspollert et al., 2002). Abe et al. (2001) reported an imbalance of supplemental lysine would possibly occur only at levels of 48 to $64 \mathrm{~g} / \mathrm{d}$. Lysine-arginine antagonism was highly unlikey to have taken place in this study due to the acceptable levels of lysine fed.

Looking closer at immune reponse, no increase in rectal temperature was observed in vaccinated calves. Further, rectal temperature did not differ among vaccinated and non-vaccinated calves. Systemic fever both directly combats pathogens as well as stimulates 
cellular immunity (Mace et al., 2011). The resulting immune stimulation results in accumulation and continued protection against a pathogen. An absence of febrile response suggests a lack of immune response to the vaccine. This was supported by observing no difference in antibody titers among vaccinated and non-vaccinated calves.

Factors influencing immune response in young calves have been well studied. Vaccine efficacy is unreliable in the presence of maternal antibodies. Seropositivity resulting from maternal antibodies may inhibit a response to vaccination early in life (Ellis et al., 2001; Endsley et al., 2003; Fulton et al., 2004). Although vaccinations were administered four weeks after arrival, maternal antibodies may have been a factor, reducing the immune response, febrile and antibody titer response in vaccinated animals. IBR antibody titers showed no difference among supplemented and control calves, or vaccinated and non-vaccinated calves. It is possible a difference in antibody titers could have been detected by sampling at a later date after vaccination. Kahrs (2001) along with Ezzi et al. (2011) reported calves can lose maternal antibodies as early as one month of age, but can have titers to BHV-1 up to six months of age.

These results ageed with Ellis et al. (2010) reporting reduced efficacy of an IN vaccination to a bovine respiratory syncytial virus challenge in seropositive animals compared to seronegative animals. Further, Patel and Didlick (2004) reported no increase in antibody titers in calves receiving a modified-live BRSV vaccine.

This study agrees with previous research in that maternal antibodies influence vaccination efficacy and should be kept in mind when developing vaccination protocol.

\section{CONCLUSION}

Bovine herpesvirus-1 is a significant pathogen contributing to economic loss in the cattle industy. Although no alterations in febrile response or IBR antibody titer levels, supplememtal lysine will alter serum lysine: Arginine concentrations in neonatal calves. These results suggest that it is possible to manipulate in vivo serum lysine concentrations, which could affect a replicating herpes virus. In vitro work has shown the replication inhibition of a herpesvirus in the presence of increased lysine levels (Maggs et al., 2000).

To further investigate the effects of lysine supplementation and herpes virus replication a live viral challenge may be valuable. Additionally, mature cattle may prove to be a better model in a vaccination challenge, removing the risk of maternal antibody interference. The results from this study encourage further work in exploration into bovine herpesvirus and lysine supplementation.

\section{ACKNOWLEDGMENT}

Appreciation is expressed to Dr. Mark Hill with Provimi Nutrition, Minneapolis, MN, for donating the milk replacer for this study.

\section{REFERENCES}

Abe, M., T. Iriki, K. Kaneshige, K. Kuwashima and S. Watanabe et al., 2001. Adverse effects of excess lysine in calves. J. Anim. Sci., 79: 1337-45. PMID: 11374556

Perez, S., M. Inman, A. Doster and C. Jones, 2005. Latency-related gene encoded by bovine herpesvirus 1 promotes virus growth and reactivation from latency in tonsils of infected calves. J. Clin. Microbiol., 43: 393-401. DOI: 10.1128/JCM.43.1.393-401.2005

Chamruspollert, M., G.M. Pesti and R.I. Bakalli, 2002. Dietary interrelationships among arginine, methionine and lysine in young broiler chicks. Br. J. Nutr., 88: 655-660. PMID: 12493087

Ellis, J., K. West, V. Cortese, C. Konoby and D. Weigel, 2001. Effect of maternal antibodies on induction of vaccine-induced immune responses against bovine viral diarrhea virus type II in young calves. J. Am. Vet. Med. Assoc., 219: 351356. PMID: 11497051

Ellis, J.A., S.P. Gow and N. Goji, 2010. Response to experimentally induced infection with bovine respiratory syncytial virus following intranasal vaccination of seropositive and seronegative calves. J. Am. Vet. Med. Assoc., 9: 991-999. DOI: 10.2460/javma.236.9.991

Endsley, J.J., J.A. Roth, J. Ridpath and J. Neill, 2003. Maternal antibody blocks humoral but not $\mathrm{T}$ cell responses to BVDV. Biologicals, 31: 123-125. DOI: 10.1016/S1045-1056(03)00027-7

Ezzi, G.A., T. Ciucci, V. Amiot, A. Wakkach and C. Blin-Wakkach, 2011. Osteoclasts modulate the balance between immunosuppression and inflammation through antigen presentation and interactions with $\mathrm{CD}^{+}{ }^{+} \mathrm{T}$ cells. J. Translat. Med., 9: 56-56. DOI: 10.1186/1479-5876-9-S2-P56 
Fulton, R.W., R.E. Briggs, M.E. Payton, A.W. Confer and J.T. Saliki et al., 2004. Maternally derived humoral immunity to Bovine Viral Diarrhea Virus (BVDV) 1a, BVDV1b, BVDV2, bovine herpesvirus-1, parainfluenza-3 virus bovine respiratory syncytial virus, Mannheimia haemolytica and Pasteurella multocida in beef calves, antibody decline by half-life studies and effect on response to vaccination. Vaccine, 22: 643-649. DOI: 10.1016/j.vaccine.2003.08.033

Hill, T.M., H.G. Bateman, J.M. Aldrich, R.L. Schlotterbeck and K.G. Tanan, 2007. Optimal concentrations of Lysine, Methionine and Threonine in milk replacers for calves less than five weeks of age. J. Dairy Sci., 91: 2433-2442. DOI: $10.3168 /$ jds.2007-0610

Jones, C. and S. Chowdhury, 2007. A review of the biology of Bovine Herpesvirus type 1 (BHV-1), its role as a cofactor in the bovine respiratory disease complex and development of improved vaccines. Anim. Health Res. Rev., 8: 187-205. DOI: $10.1017 / \mathrm{S} 146625230700134 \mathrm{X}$

Kahrs, R.F., 2001. Infectious Bovine Rhinotracheitis and Infections Pustular Vulvovaginitis. In: Viral Diseases of Cattle, Iowa State University Press, Ames, pp: 159-170.
Mace, T.A., L. Zhong, C. Kilpatrick, E. Zynda and C. Lee et al., 2011. Differentiation of CD8 T cells into effector cells is enhanced by physiological range hyperthermia. J. Leu. Bio., 90: 951-962. DOI: 10.1189/jlb.0511229

Maggs, D.J., B.K. Collins and J.G. Thorne, 2000. Effects of L-lysine and L-arginine on in vitro replication of feline herpesvirus type-1. Am. J. Vet. Res., 61: 1474-1478. DOI: 10.2460/ajvr.2000.61.1474

Nandi, S., M. Kumar, M. Manohar and R.S. Chauhan, 2009. Bovine herpes virus infections in cattle. Anim. Health Res. Rev., 10: 85-98. DOI: 10.1017/S1466252309990028

Patel, J.R. and S.A. Didlick, 2004. Evaluation of efficacy of an inactivated vaccine against bovine respiratory syncytial virus in calves with maternal antibodies. Am. J. Vet. Res., 65: 417-421. DOI: 10.2460/ajvr.2004.65.417

Raaperi, K., I. Nurmojo, T. Orro and A. Viltrop, 2010. Seroepidemiology of Bovine Herpesvirus 1 (BHV1) infection among Estonian dairy herds and risk factors for the spread within herds. Prev. Vet. Med., 96: 74-81. DOI: 10.1016/j.prevetmed.2010.06.001

Yates, W.D., 1982. A review of infectious bovine rhinotracheitis, shipping fever pneumonia and viralbacterial synergism in respiratory disease of cattle. Can. J. Comp. Med., 46: 225-63. PMID: 6290011 